\title{
REINFORCING MYTHS ABOUT WOMEN IN PHILIPPINE CULTURE \\ Semiotic Analyses of the Sexbomb Girls in Eat Bulaga's Laban o Bawi
}

\author{
Trina Leah Mendoza \\ University of the Philippines Los Baños \\ tltmendoza@devcom.edu.ph
}

\begin{abstract}
Movie and TV stars are an influential part of Philippine society. Not only do they entertain audiences with their television shows or movies, but their private lives and actions are arguably as interesting to the public. Celebrities and stars are admired, idolized, and looked up to by many of their followers, such that their values and actions can greatly influence their fans. However, their images may hold various meanings that are not evident to many people. This study analyzes a group of unconventional stars that changed the landscape of noontime viewing - the Sexbomb Girls - using a semiotic approach. It seeks to reveal the different images of women portrayed by the Sexbomb Girls, and understand how media can reinforce myths. The Sexbomb Girls were a social phenomenon and a product of production that depicted binary oppositions and metaphors: virgin/vamp, loud woman, and ordinary woman. These signs, binary oppositions, and metaphors served as myths that naturalized, influenced, and reinforced sexy female background dancers into becoming an ordinary part of noontime and game shows. Because they appeared six days a week in Eat Bulaga, the Sexbomb Girls have desensitized the Filipino masses such that seeing sexily clad background dancers in these shows has become ordinary and acceptable.
\end{abstract}

\section{Keywords}

binary oppositions; metaphors; semiotics; Sexbomb Girls; signs; social phenomenon 


\section{About the Author}

Trina Leah Mendoza is an assistant professor at the Department of Development Broadcasting and Telecommunication, College of Development Communication, University of the Philippines Los Baños (UPLB). She has degrees in BS Development Communication from UPLB, MA Media Studies (Broadcasting) from UP Diliman, and is currently finishing her PhD in Development Communication from UPLB. Before she started teaching at UPLB in 2014, Trina was a senior communication specialist at the International Rice Research Institute (IRRI), Los Baños, Laguna, and developed communication strategies and materials to promote best rice technologies and practices in Southeast Asia. She received the 2009 IRRI Award for Outstanding Research Support. Trina has also worked as a writer and editor at the Philippine Council for Agriculture, Aquatic and Natural Resources Research and as a writer and producer for MYX, ABS-CBN. Her research interests include development communication, science communication, media studies, community communication, participatory video, and pop culture. 


\section{INTRODUCTION}

In the Philippines, stars play a significant part in people's lives. They not only provide entertainment through their latest movies, TV shows, or songs, but in many cases, their private lives attract more attention and interest from the Filipino audience. Many Filipino fans aspire to become like their favorite stars that they mimic their actions and fashion sense. The dream of fame and fortune has attracted many Filipinos, such that thousands queue in events organized by major TV networks in the hope of being chosen to join reality-based star searches, such as the television series, Starstruck created by GMA Network in 2003, and ABS-CBN's Pinoy Big Brother, a local version of the Big Brother franchise, which was first aired in the Philippines in 2005. Social media has now made it even easier to gain access into a star's everyday life, such that these stars' opinions, values, and even the smallest details of their lives can influence thousands. Alongside with reality-based star quests were searches for background dancers to perform in noontime television shows such as Eat Bulaga, Magandang Tanghali Bayan, and Wowowee.

The early 2000 s witnessed the phenomenal rise of the Sexbomb Girls. The Sexbomb Girls started as background dancers in 2000, performing until 2011 in the noontime game show Eat Bulaga, the longest-running noontime show in the Philippines. They quickly moved past being background dancers in less than 5 years and became recording artists and lead stars in their own soap opera Daisy Siete (which aired for 7 years and lasted 26 seasons) (Parungao) and in their own movie, Bakit Papa? Their album Unang Putok was a four-time platinum awardee, followed by three more hit albums - Wish ko sa Pasko, Round Two, and Bombthreat-making them one of the country's best-selling female groups. From 2002 to 2008 , they were awarded as the Most Popular Dance Group by the Guillermo Mendoza Memorial Scholarship Foundation (Parungao). They also endorsed several products such as Rev-X diesel and Crimson clothing line. The Sexbomb Girls' song Bilog na Hugis Itlog was used in an infomercial for the 2010 national elections (Catolico). Columnist and socialite Tim Yap compared the Sexbomb Girls to Dolphy, calling their success "a breakthrough for the local reality celebrity," as they were among the first ones to shape the genre with their life stories told in primetime drama shows. They were also compared to England's Spice Girls, who rose to fame in such a short time (Asuncion 46-52). Known for their seductive gyrations and skimpy clothing, the Sexbomb girls were said to be widely admired by men, women, and children, both young and old. Young children, both girls and boys, copied their dance steps during playtime and in school presentations and family gatherings. Yap believed them to be so iconic that he predicted that kids from that generation will look up to them in the same way that his generation looked up to the Bellestar Dancers of the past. In the context of Philippine media, the Sexbomb Girls have revolutionized the way 
game shows and noontime shows are treated in the Philippines, such that these shows have since then added sexy female background dancers to their programs.

Stars are not only entertainers; they are a social phenomenon (Dyer 6). Alberoni defined stars as a group of people who have very limited or non-existent institutional power, but whose way of life and actions attract considerable and sometimes, a maximum degree of interest (Dyer 7). Stars are very influential in representing people in society: how people are represented in media will influence (even if only to reinforce) how people are in society. They have privileged roles in defining social roles and types, which have real consequences in terms of how people believe they can or should behave (Dyer 7).

The creation of stars is greatly influenced by texts which usually refer to messages that have been recorded in some way (through writing, audio- and video-recording, etc.) A text is a group of signs, such as images, words, sounds, and/or gestures that are constructed and interpreted with reference to the conventions associated with a genre and in a particular medium of communication (Chandler 2). According to Mitchell, it is very difficult to unearth the impressions, especially the depth and influence, brought upon by artists on the masses because of the various and yet interconnected notions of "picturing, imagining, perceiving, likening, and imitating" (1).

The Sexbomb Girls can be considered as images or texts created by media companies-a phenomenon of production built using a large amount of money, time and energy in publicity, fan clubs, and promotion to build up their star images. These media texts projected many images, signs, symbols, meanings, and ideology (set of beliefs), which may or may not have been noticed by the regular Filipino viewer.

Recent published studies have analyzed the images in media texts of various Philippine icons and their projected meanings and symbolisms. In his study of archetypes and Philippine epics, Cruz described Ninoy Aquino not only as a hero killed on a tarmac, but as a symbol for Filipinos tired of being taken advantage of and being lied to (207-216). The action films of Joseph Estrada "depicted characters in solidarity with and providing leadership for the masses" (Tolentino, "Masses, Power, and Gangsterism" 257-271). On the other hand, Judy Ann Santos's portrayal of women in teleseryes depicted their strength despite adversity, their rise from the marginalized and oppressed to women of power, stature, and education (Sanchez $353)$.

This study analyzes the images of a Philippine media phenomenon in the early 20oos-the Sexbomb Girls-according to social codes (bodily codes, commodity 
codes, and verbal language), and textual codes, specifically, filmic techniques, using a semiotic approach (i.e., a study on their verbal and nonverbal signs). The study aims to (a) describe the social and textual codes in the images, (b) surface the denotative and connotative meanings in the codes, (c) examine the binary oppositions and metaphors depicted by their images, and (d) discuss other representations of women in Philippine media during the 20oos. This research further aims to show media's capacity to create various meanings and symbolisms through their products. No similar study on the Sexbomb Girls has been published yet.

\section{METHODOLOGY}

The study adopts a qualitative approach, and thus focuses intensively on probing deeper into a particular phenomenon: the Sexbomb Girls. The focus of this qualitative approach is on the occurrence of its analytical objects in a particular context, and thus has no intention of going beyond its object of study. This study seeks to understand and interpret through a study of signs, symbols, and meanings. This is a cross-sectional study on the images of the Sexbomb Girls during the height of their popularity (June to August 2004), and a discussion of other representations of women in media in the 20oos, as well as the current trends that the Sexbomb Girls have influenced over a decade later in the 2010 .

Apart from the past episodes of Eat Bulaga that the researcher had watched prior to the study, the Laban o Bawi segments from the weeks of July 13-18, July 22-24, July 26-31, and August 2-7, 2004, were analyzed. Laban o Bawi was a popular contest because it was one of the first noontime show segments to give out $\mathrm{PhP} 1$ million as its jackpot prize. Contestants need to answer a series of trivia questions in the elimination round. In the jackpot round, the contestant must perfectly arrange a row of boxes to win the highest possible jackpot prize.

These three consecutive weeks were chosen purposively because the Sexbomb Girls had just launched their last album Bombthreat and were using different promotional gimmickry (e.g., dancing to their new songs) during the Laban o Bawi segment. The July 26 episode was video-recorded so that the researcher could review and take still photos of the segment. This particular date was chosen since it fell on a Saturday and all 20 members were present. (The group was not always complete on weekdays due to other engagements such as tapings for Daisy Siete).

Denotative and connotative meanings of Chandler's social codes (bodily codes, commodity codes, and verbal language), and textual codes, specifically, 
filmic techniques are identified in the examination of this text (154-160). These commodity codes are treated as first-level signifiers. Denotative or commonly known meanings are then determined by the researcher and supported with related literature. In the case of the text being examined, commodity codes include their costumes and appearance-such as long, flowing hair-which then signifies femininity (denotative meaning and first-level signifier). The denotative sign and signified (femininity) then becomes the second-order signifier.

Connotative meanings are also provided by the researcher based on related literature; they are then categorized into themes. As an example, long, flowing hair may hold other meanings such as good health, economic status, and youth.

Structural analysis has been very helpful in semiotics, and vice-versa. Mainly through the influence of Roman Jakobson, the primary analytical method used by many structuralist semioticians involves identifying binary or polar semantic oppositions such as us-them and public-private in texts or signifying practices (Chandler 101-107). These binary oppositions serve as classificatory systems, which transform what are perceived as natural categories into cultural categories, and serve to naturalize cultural practices (Chandler 102-106). Among the binary oppositions projected by the images of the Sexbomb Girls' images, as proposed in this research, is the dichotomy between the virgin and the vamp.

Guided by related literature, this research also identifies particular metaphors in the images of the Sexbomb Girls. Metaphors are like myths, which reflect and influence beliefs and values in society. In semiotics, a metaphor involves one signified that acts as a signifier referring to a different signified (Chandler 127).

\section{RESULTS AND DISCUSSION}

\section{Meanings in Signs and Symbols}

The Sexbomb Girls were first introduced as background dancers in a game segment of the noontime show, Eat Bulaga. This was where they were named as Sexbomb Girls, when TV host Joey de Leon gave them the monicker, since they were always dancing to Tom Jones's song, Sexbomb, which had been popular at the time. While contestants participated in the contest, the Sexbomb Girls either chanted, sang their latest song, or showed-off their latest dance move or short dance routine (see Figure 1). 


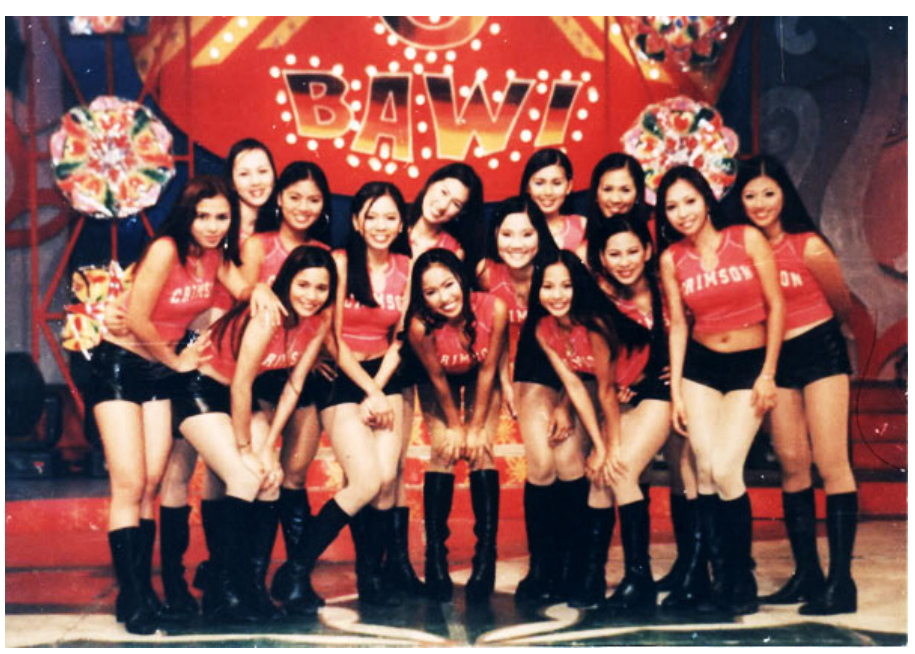

Fig. 1. Sexbomb Girls in the Laban o Bawi segment of Eat Bulaga.

Photo from www.fhm.com.ph.

The denotative and connotative meanings of the images the dancers have been identified through social and textual codes. Social codes include commodity codes (e.g., fashion and costume), verbal language, and bodily codes. These codes are all components of semiotics. According to Chandler, semiotics involves not only the study of what we refer to as "signs" in everyday speech, but of anything that stands for something else - these are words, images, sounds, gestures, and objects. A sign is also a combination of a signifier and a signified (Littlejohn 58). A signifier is the form a sign takes, and the signified is the concept to which it refers (Chandler 18). The study examines the signifiers and signifieds that make up the signs to reveal the denotative and connotative meanings in the images. Obvious or observable meanings are also called denotative meanings, which are described as definitional, literal, or "commonsense" meanings of a sign (Panofsky in Chandler 140). Hidden meanings are also called connotative meanings, which refer to the sociocultural and "personal" associations (ideological, emotional, etc.) of the sign. These are usually related to the interpreter's class, gender, age, ethnicity, and so on. Signs are more open to interpretation or "polysemic" (many meanings) in their connotations than their denotations (Wilden in Chandler 140).

Connotative meanings are related to Roland Barthes's concept of the myth, which is seen as the dominant ideologies or sets of beliefs in society. Myths help people make sense of the world. Through signs and codes, myths naturalize the cultural or make dominant cultural and historical values, beliefs, and attitudes seem natural, obvious, or normal. Barthes explains that the orders of signification-denotation and connotation-combine to produce ideology (Chandler 144-145). 
Commodity codes. Similar sexy clothing and hairstyles - that is, long, flowing hair-make up the commodity codes that identify the Sexbomb dancers' fashion. All the Sexbomb Girls wore the same clothes and sported similar hairstyles in performances, especially on the segment Laban o Bawi, except for one member, Rochelle, who is usually given a slightly altered or different piece of clothing than the rest. She dons a short skirt, when everyone is in pants; denim jeans when the rest are in jogging pants; or a cropped shirt when others are in regular shirts. In the clips examined, Rochelle also wears her hair down, while everyone else is in braids or ponytails. Wearing slightly different clothes and hairstyle, or generally being different in a group, denotes that that person is special and plays a significant role in the group. Rochelle is clearly shown as the leader based on her physical appearances. However, being different or singled out like Rochelle also connotes superiority, or having an advantage or edge over others.

Long hair usually denotes femininity in women. History shows that hair is a symbol of femininity-a symbol that dates back to at least the ancient Greeks and Romans. Archaeologist Elizabeth Bartman says that despite the image of the "bearded, long-haired Ancient Greek philosopher," Roman women kept their hair longer than men. On the other hand, men who give too much attention to grooming their hair risked being mocked for appearing effeminate (Fabry). During the Civil War, hundreds of women soldiers would cut their hair and disguise themselves as men because they were not allowed to battle (Ellery). In the Philippines, long, flowing hair is a characteristic of Jose Rizal's Maria Clara, who represents an image of chaste Filipina womanhood (Manalo). Psychologists say that in modern times, long hair sends a message of femininity and softness-not weakness-and make men feel less threatened by their female counterparts who remain to be their competition in the workplace (Slade). In some cases, long hair for women might also connote many meanings aside from femininity. Sociologist Anthony Synnott says that hair is a personal symbol with extreme social significance. Studying St. Paul's Letter to the Corinthians, which reads: "Doth not nature itself teach you that if a man has long hair it is a shame unto him? But if a woman has long hair, it is a glory to her," Stenn interprets that a woman with long hair means that she is healthy and has money to have it taken care of. Thus, long hair means good health and a comfortable status in life (Fabry). Furthermore, psychologists say that a woman's longer hair recalls the vitality of youth.

Revealing clothing usually denotes sexiness and sophistication in women. However, sexualization of women through provocative clothing has become very pervasive in media and popular culture, such as in advertisements and magazines. Between 2006 and 2016, women in advertisements were shown in sexually revealing clothing six times more than men, which dropped to five times more than men in 2017. On the other hand, the number of female characters in 
advertisements wearing sexually revealing clothing remain the same: 1 out of 10 characters (Richards). A longitudinal content analysis of men and women's images on the cover of Rolling Stone magazine from 1967 to 2009 also shows that women continue to be more frequently sexualized than men (Hatton and Trautner 1).

Young women then adopt these sexualized images in their attempts to look stylish or stay on-trend, without thinking of the possible consequences (Whitbourne). Studies show that sexy women are perceived to be less competent at work, because by wearing overtly sexualized clothes, they exude that feminine stereotype of someone weak, gullible, dependent, and emotional, and these weaknesses undermine her ability to be taken seriously by men (Whitbourne).

Verbal language codes. Codes that indicate verbal language include chanting loudly, singing novelty songs, chanting in unison, and chanting towards contestants. The Sexbomb Girls are known for their loud, playful chants, screams, and language, which are meant to attract the attention of the viewers and engage them in the contest during the game segment. Most people denote loudness as unruliness or lack of finesse. In the Philippine context, one may be reminded of jeepney barkers calling for passengers or market vendors selling their goods. According to Van Leeuwen, speaking loudly is a way of conveying a message to a public and not just a few people (79). In comparing the two, the jeepney barkers shouting to prospective passengers and the Sexbomb Girls chanting loudly both aim to attract the attention of their targeted audiences. However, the Sexbomb Girls' loud chants may connote a deeper meaning than simply conveying their message to the public. In Rolando Tolentino's interpretation of then Filipino sexy star Rosanna Roces as the epitome of the "loud woman," he describes her as using her "loudness" to subvert the traditional rules in gender and kind ("Rosanna Roces"). In the same manner, the Sexbomb Girls use their loudness to challenge the current system and let women take centerstage instead of bigger stars or their male counterparts who traditionally enjoy the limelight ("Rosanna Roces"). For the first time in Philippine TV history, female background dancers received an extraordinary amount of attention that was not previously given to them. Through their loud, playful chants, these women commanded attention and admiration from thousands of fans who would ordinarily idolize the bigger stars - the matinee idols, dramatic actors, action stars, or love teams. Even in 2018, their loud, playful chants remained iconic and influential, with TV host and comedian Vice Ganda sometimes leading Sexbomb-like chants with his team while playing Cash-Ya, a game segment in ABS-CBN's noontime show It's Showtime, where contestants try to beat the other team by guessing and attempting to fit as many players in an object such as a makeshift telephone booth.

Aside from their chants on Eat Bulaga, the Sexbomb Girls also released several memorable hit songs, which included Bakit Papa and The Spageti Song. Bakit Papa, 
from the album Unang Putok (2002), is their first hit song and the title of their movie. The song is about a girl asking a former lover why he left her; she professes her undying love for him despite the attention and material gifts she receives from other men. The song makes use of the intertextuality of texts to its advantagereferencing the names of the other male hosts of Eat Bulaga (i.e., Bossing, Anjo Yllana, Joey, Jimmy, Kiko, and Allan K.) as the men who shower the woman with gifts and affection. The chants in the song- "Laban, laban, o bawi, bawi" and "Aww!"-successfully remind the listeners of the popular segment in Eat Bulaga. This first novelty song, which makes use of a catchy tune and simple lyrics, is made more memorable to the public as it highlights the Sexbomb Girls' association with the famous noontime show. This is the strategy employed by the producers and managers of the female group to ensure that their first song would be a hit.

Their second hit, The Spageti Song, forms part of their second album Round Two released in 2003. Eat Bulaga host Joey de Leon lends his voice to the track as the character T'yo Pot, his gay character in a defunct sitcom in GMA. In the song, he teaches the girls how to exercise to become sexy. Composer Lito Camo wrote this song which was inspired by a children's game of the same title. This song, with its catch phrase, "Spageting pababa, pababa nang pababa, spageting pataas, pataas nang pataas," and with matching gyrating movements, made a significant mark with the Filipino masses, both young and old. Although the lyrics seem nonsensical, its lively beat sung by these scantily clad dancers in gyrating motions, and packaged as a light-hearted song for children, made the song a hit that has earned for its producers. Upon closer examination of the lyrics, particularly T'yo Pot's side comments, he actually talks about how rival network ABS-CBN continues to copy Eat Bulaga (e.g., O meron ba sila n'yan? Gagayahin na naman yan, Pataas naman tayo ha, ang rating ha, Pababa nanaman sila, syempre). His side comments were meant for the then rival show MTB and G-Girls, who were pitted against the Sexbomb Girls.

Their most popular songs Bakit Papa and Spageti Song reflect and reinforce a significant aspect of the Sexbomb Girls' image of being a sexy female group who sang novelty songs (some laced with sexual innuendo) that cater to audiences of all ages. The sexy costumes and gyrations are meant to attract the men and inspire women, and the lively, playful songs aim to entertain the youth. Their other songs such as Tequila, Stupid Ka Rin, I'm Not That Girl, and Chuvang Papa had lyrics that were sexually suggestive and themes meant for a more mature audience, such as betrayal, casual sexual relationships, and the physical abuse of women. These songs were not launched on Eat Bulaga-perhaps to maintain the sexy yet still decent images of the Sexbomb Girls meant for a wider audience. All these different facets contribute to the Sexbomb Girls' image as a product of production, carefully planned and implemented by their management to create an image that will not 
only attract audiences, but more importantly, increase the ratings of programs, records sales, and movie ticket sales.

Examining the text from another perspective, a choir or dance group is also expected to perform harmoniously and simultaneously; thus, it is required of the Sexbomb Girls (being a professional dance group) to perform the same dance steps in synchrony and to chant the same messages as a group. The Sexbomb Girls sing in social unison, where all voices sing the same notes. What is worth noting is that saying the same things as a group has both positive and negative connotations. On a positive note, it can mean solidarity, consensus, and a positive sense of joint experience and belongingness in a group. Negatively, it could signify conformity and a lack of individuality (Van Leeuwen 79). As Van Leeuwen notes, individual timbres can no longer be distinguished. Thus, while the Sexbomb Girls seem united since they look the same and say the same things, the public may perceive them as a collective with similar views and beliefs, instead of individuals with diverse ideologies. Furthermore, social unison becomes an important means of disciplining joint activity, where no one is allowed to opt out or act out of step. As such, the Sexbomb Girls' individual actions and opinions are controlled because they are part of a group. The Sexbomb Girls always aim to please the fans and obey their management; they work as one group so as not to deviate from what is expected of them.

Chanting messages to the contestants such as "Upo! Upo!” (Sit down, sit down!) or "Tsugi time!" (Time to go!) endears the Sexbomb Girls to the Eat Bulaga audience. Their animated and energetic chants engage the audience into chanting with them. At times, they even seductively gather around a male contestant and gyrate in front of him. While the Sexbomb Girls' one-liners and improvised chants appear clever and funny to some, they can also be interpreted as embarrassing or demeaning-particularly for the contestants. In their attempt to look cute and witty to the audience, the Sexbomb Girls sometimes make the contestants their object of fun. The Sexbomb Girls can be compared to the beautiful Filipino comediennes in films. According to Atienza, only beautiful women are allowed to be loud and boisterous, because their beauty can make up for their lack of finesse (13-15). Their beauty, popularity, and wit allow them to get away with lashing at men, while their ordinary counterparts would probably warrant a beating or abuse from the men they put down.

Bodily codes. Bodily codes such as gestures, postures, and facial expressions are also analyzed, and the codes used by the Sexbomb Girls include their signature pelvic thrust (gesture) and the act of looking at the camera (facial expression). Their signature pelvic thrust and chants are meant to attract and engage the audiencecommanding some influence when even little girls come to imitate their every 
step. Consequently, these dance steps can be seen as being sexually suggestive, also attracting the male audiences. The Sexbomb Girls appear cute, playful, seductive and at ease with the camera as they posed in front of it. Looking into the camera is a privilege that not all narratives have. In soap operas, movies, and other narratives, looking at the camera is avoided to depict realism (but there are exceptions to the rule). As such, the Sexbomb Girls remain in a position of privilege, looking into the camera. As emphasized in a different context by Laura Mulvey's essay, the Sexbomb Girls become the subject of the (male) gaze, yet they subvert it, enjoy the gaze, and return the favor by looking into the camera as well (381-389).

Textual codes. Textual codes in semiotics refer to narrative, characterization, themes, setting, iconography, and filmic techniques. This study only examines filmic techniques, particularly camera shots and angles, to analyze the Sexbomb Girls during the Laban o Bawi segment, as these are found to be most appropriate in the study. The other textual codes (i.e., narrative, characterization, themes, and setting) are typically used in studying other genres such as the melodrama, film, or teleserye. These codes have also been used by the researcher to analyze the Sexbomb Girls in their soap opera titled Daisy Siete, although it is not part of this paper.

A long shot from a high angle shows the totality of the scene. It gives the viewer a sense of "being there" and knowing what goes where. It establishes the scene in one shot. However, there are several meanings that are not obvious at one glance or upon passive viewing. The long shot, usually at the start of Laban o Bawi, depicts that portion as an organized contest, similar to a ritual where the contestants are given the most importance by placing them in the middle, while the dancers remain on the sidelines. The hosts, while also placed at the side, are given importance by placing them in a separate frame which is shown throughout the game. The sizes of frames such as close-up shot, medium shot, long shot, and so on, create a certain distance between the viewer and the images represented in the picture. According to Hall, the long shot portrays people as though they are outside the viewer's social orbit, either because they are strangers or because they are higher or lower in status (110-120). The vertical angle in camera movement is connected to imaginary power relations. A high-angle shot directs viewers to look down at the subject, creating an illusion that the subject is inferior to the viewer (see Figure 2).

The long shot of the girls in one frame gives the audience a view of the girls from head to toe. The totality of the girls is shown: their costumes, bodies and movement, and unrecognizable faces. The normal angle makes them appear as a group that is of the same status as the viewers because it is shot at eye level. However, although they are seen from the position of an equal, the shot emphasizes their bodies. Their faces are unrecognizable because the long shot is quickly cut to a different 


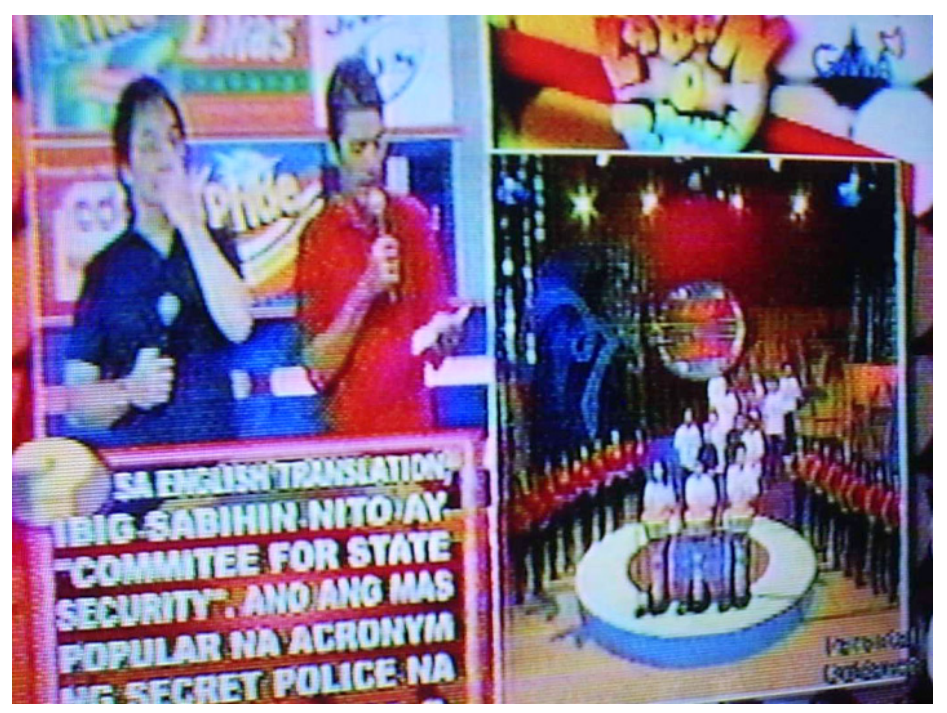

Fig. 2. High angle, long shot of the Sexbomb Girls at the start of Laban o Bawi segment.

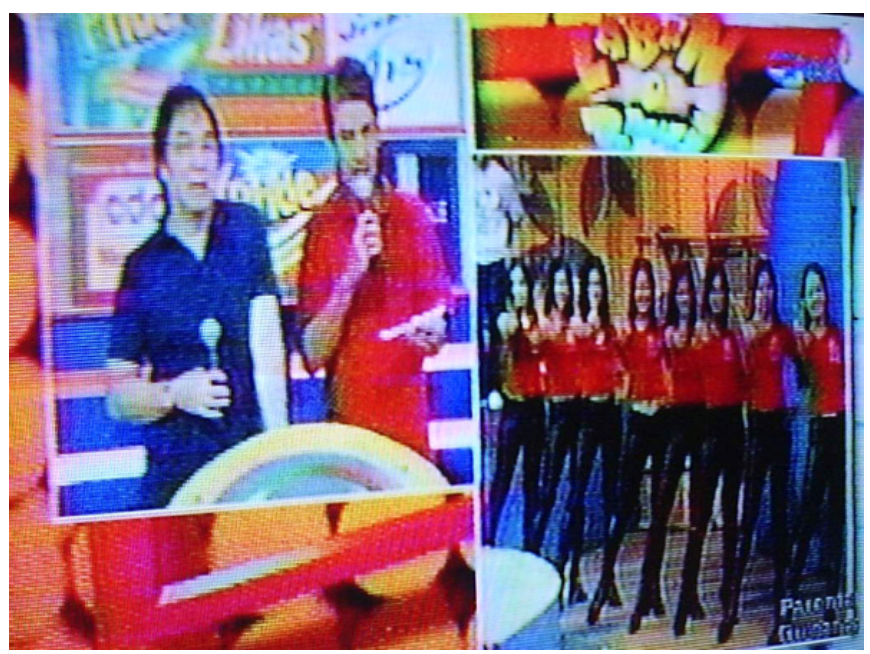

Fig. 3. Normal angle, long shot of the Sexbomb Girls.

shot, but their bodies are more distinguishable. Thus, their bodies are given more importance than their faces and identities (see Figure 3). 


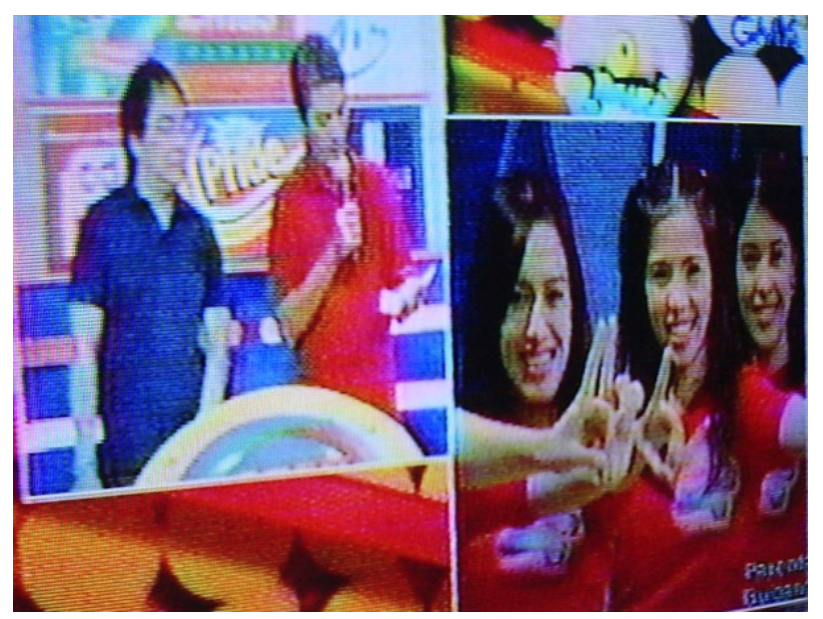

Fig. 4. Normal angle, medium shot of some of the more popular girls.

A normal angle medium shot shows a fewer set of girls from an equal position and gives more exposure and importance to the girls' faces and identities. According to Hall, medium shots create more formal kinds of imaginary relations, similar to social distance which is more business-like and for more formal interactions (110120). However, a medium shot of the Sexbomb Girls is not done to establish formal interactions, but to give the viewers a clearer view of the members. This time, the camera focuses not on their bodies, but on their faces. This shot, done several times throughout the segment, makes them more recognizable to the public (see Figure 4).

A close-up shot tightly frames an object or a person, showing less of the background and focusing more on facial expressions and details. This shot also provides the most exposure and importance to the girls' faces and identity. Most often, the subjects of the close-up shots are the most famous Sexbomb Girls members, Rochelle and Jopay; this further increases their popularity and charisma with the viewers. Sometimes, the less popular girls are also featured in close-up shots. However, a close-up also connotes intimacy between the viewer and the star. The close-up shot in the world of TV and film, which shows only the head and shoulders in sharp vision, corresponds to personal distance. It makes the viewers feel "close" to the stars. There is an imaginary intimacy between the viewer and the subject of the close-up. That is why Rochelle was always featured in a close-up-so that the viewers, most of whom are fans of Rochelle, would be more drawn to her and would continue to watch the show to see her more. Other times, Eat Bulaga featured lesser-known or newer members of the Sexbomb Girls, so as to "introduce" them to the public and create new imaginary relationships with them (see Figure 5). 


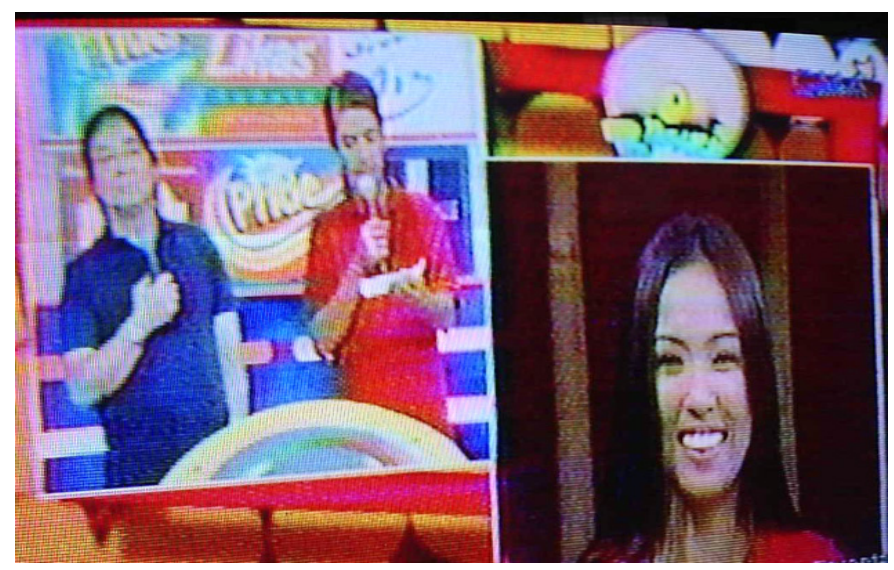

Fig. 5. Close-up shot of Rochelle, the most popular member of the Sexbomb Girls.

\section{BINARY OPPOSITIONS AND METAPHORS}

The study also identifies the social and textual codes in the images of the Sexbomb Girls in Laban o Bawi to surface the binary oppositions and metaphors in the codes. Binary oppositions emphasize the differences between signs rather than the similarities. Similar to myths, the binary oppositions that people employ in their cultural experiences help generate order in complex experiences. People have believed in binary oppositions since at least the classical times (Chandler 101107). For example, Aristotle in Metaphysics developed as primary oppositions the following: form-matter, natural-unnatural, active-passive, whole-part, unity-variety, before-after, and being-not being (Chandler 101-102). Rudyard Kipling observes that people have a tendency to divide between "us" and "them." Paired signifiers such as female-body and male-mind are parts of deep or hidden structures of texts that shape preferred readings. Binary oppositions serve as classificatory systems which transform what are perceived as natural categories into cultural categories. Binary oppositions also help in naturalizing cultural practices (Chandler 102-106).

The denotative and connotative meanings serve as indicators that are then grouped according to several corresponding binary oppositions and metaphors that the former best fits in. The binary opposition that is most apparent in the image of the Sexbomb Girls is that of the virgin/vamp. Gallagher describes the virgin image as that of a woman usually at home who is subordinate, sacrificial, and pure (in Benedict 21-22). Indicators of the Sexbomb Girls that fall under this category are the codes of conformity, of being traditional, and of subservience. 
Virgin/vamp. The girls project the binary opposition of a virgin/vamp; innocent yet seductive. Their sweet smiles and shrill, flirty screams serve as strategies to seduce the men, while simultaneously entertaining the children as well. Their youthfulness and innocence-and the fact that they sing children's songs-make them appealing to the children, yet they are packaged as sexy women to attract the men. It is worth noting, however, that while they project themselves as sexy and seductive, they did not pose nude in magazines or posters.

Their image as “virgin” can be compared with Tolentino's analysis of Sharon Cuneta as the perpetual virgin, who is "eternally meek, subservient, patient, the proverbial model of kindness and/or goodness" ("Sharon Cuneta" 63). On the other hand, the Sexbomb Girls also display characteristics of being, "vamp." Reyes described the vamp as:

[the] fantasy figure that promises the viewer so much.... She is the object of desire, a condition which she actively encourages by striking highly suggestive poses and wearing extremely provocative clothes. She is the fetish that appears regularly, whetting the viewer's appetite and prompting him/her to stay glued to the channel. Sexuality for sale is the message communicated by both the visual and aural strategies these shows employ. (169)

Metaphors, especially dominant ones, tend to reflect and influence values in a culture or subculture. In semiotics, a metaphor involves one signified that acts as a signifier referring to a different signified (Chandler 127). It is something concrete used to represent an idea, quality, or condition. For example, an orchestra rehearsal which dramatizes the revolt of an orchestra against its conductor is a metaphor for the disintegration of society and a warning that the result of anarchy is dictatorial control (Wolf in Barnhart et al. 1304). Metaphors vary in different cultures but they are not arbitrary, and are instead derived from people's physical, social, and cultural experiences. They extend into myths that reflect, influence, or reinforce values and beliefs in a culture (Chandler 129).

The metaphors that surface in the images of the Sexbomb Girls are that of being a loud woman and an ordinary woman. Their verbal language codes, particularly their loud chanting and domineering attitude towards the contestants, give the image of being loud women.

Loud woman. The Sexbomb Girls can also be compared to Rolando Tolentino's image of Rosanna Roces as the loud woman ("Rosanna Roces"). Roces uses her body and naughty behavior; she uses double-talk to attract attention and subvert traditional patriarchal views on gender. The girls, on the other hand, utilize their virgin/vamp image, along with suggestive movements and language, to lure both 
young and old, and to subvert the traditional expectations that a Filipino woman must behave and speak properly and dress modestly. Their loud chanting to the audience and contestants in particular, break the stereotype of Filipino women as quiet, demure, and submissive; instead, they create an iconic image of a group of sexy women loudly chanting "Laban, laban, o bawi, bawi." This is something that the Filipino audience has only seen for the first time on noontime television. They have created a "Sexbomb culture" that extends beyond the masses to all sectors of society, where children have all adored and idolized them, women and teenagers have dressed like them, and men have fantasized about them (Asuncion 46-52; Ramos 16-19).

Ordinary woman, rags-to-riches. Physically, their brown complexion, Filipino facial features, and their simple backgrounds, give the Sexbomb Girls the image of the ordinary woman. The girls thus become reminiscent of Tolentino's reading of the image of Judy Ann Santos as having the aura of the ordinary ("Judy Ann" 103109). Like Santos, these girls did not fit the mold of a beauty queen, nor were they the conventional mestiza actresses that are commonly preferred in mainstream media. Instead, they speak candidly, scream wildly, use the words "papa" and "chuva," and gyrate endlessly on national television. Furthermore, they are marketed as singers of novelty songs, which target and are appreciated by the masses. These are some reasons why they have become more loved by the public compared to the usual glamorous celebrities; they are unpretentious and "ordinary." Their ordinariness make them more "human" and real to the public, as though the Sexbomb Girls might be their best friends or sisters. The girls appear humble and approachable. Furthermore, they inspire people with their rags-to-riches stories-narratives that suggest that their ordinary fans could become as successful as the Sexbomb Girls. The dance group is composed mostly of ordinary teenage girls who did not finish school and came from the lower to middle classes. They are uncomfortable speaking in English. The Sexbomb Girls, along with their novelty songs and sometimes tacky outfits, have been labeled as "jologs," which according to the Urban Dictionary ("Jologs"), is a term for someone who is tacky, but it is implied in a negative tone and usually refers to people from a lower class. However, the "jologs" image work to their advantage and make them more relatable to the masses.

\section{OTHER IMAGES OF WOMEN DURING THE SEXBOMB PHASE}

In the 200os, when the Sexbomb Girls' stardom peaked (between 2002 and 2011), Philippine media continued to present different images of women across genres. In a study that analyzes the differences in gender representations, researchers find that representations of women in 254 unduplicated primetime Philippine TV 
advertisements from 2010 still adhere to the conventional stereotypes (Prieler and Centeno). While the study finds that there are more female than male primary characters $(58.3 \%$ vs $44.6 \%)$, more females are seen at home ( $45.9 \%$ vs $24.5 \%)$, and they are more often suggestively dressed ( $52.7 \%$ vs $6.6 \%)$. Images of the Filipino woman in several Filipino films during the decade of the Sexbomb phenomenon have also been studied.

In her 2010 study of the representation of women in Filipino religion-themed films, Cabanawan finds that the female protagonists have also been portrayed as objects for the male gaze and as virgins/vamps-which are images similarly portrayed by the Sexbomb Girls. Angelica Panganiban's character, Malen, in the film Santa Santita (directed by Laurice Guillen in 2004) is described as having captured the virgin/vamp divide, exuding both sexual and innocent beauty in the film. Cabanawan also says that the title itself highlights the dichotomy, which she views as a retelling of the story of Mary Magdalene, the prostitute who became a disciple of Jesus - the vamp turned into a virgin (53). The film's camera shots also make use of Mulvey's "male gaze," which is similar to how the Sexbomb Girls are shown in Eat Bulaga's Laban o Bawi. The virgin and vamp images are also depicted in Joel Lamangan's 2004 film Ang Huling Birhen sa Lupa (Cabanawan 49). The study observes that the women still dominate fictional narratives, and that in a melodramatic genre, virgin and vamp characters will always co-exist. On the other hand, in some of the films studied, women are also portrayed as supernatural and capable of performing miracles. From being ordinary, weak, and underprivileged, women eventually become supernatural, powerful, and socially relevant, but eventually, they return to being ordinary (Cabanawan 54-55, 59).

Women are also portrayed as articulations of nation-space and an agency of insularity, according to a study of selected films by Filipino filmmaker Jeffrey Jeturian, released between 1999 and 2006. The woman is defined as one metaphor or trope used to articulate, negotiate, and construct the nation (Tan 5, 8). Tan describes insularity as the sense-making operations of a nation to outside forces (e.g., the West or the First World with imperialist ends). According to Tan, "women, as agents of insularity, are thus the embodiment of a national discourse that is aimed at 'survival and emancipatory purposes' of the collective" (4). The same themes are featured in the three films Pila Balde (1999), Tuhog (2001), and Kubrador (2006): poverty in urban slums, the struggle to survive, and strong female characters. The female protagonists are all hardworking, persevering, determined and strong, and they face difficulties and struggle against poverty and violence. However, forces in society such as politics, economy, and culture, always prevent them from fully emancipating themselves. At the very least, audiences are assured that the women survive these obstacles because of their strengths (Tan 25, 29). Media's representation of women (particularly in film) are thus not only confined to gender-related roles 
but has implications on the national economic and political discourses (Tan 11). In Tan's analysis, since the films' female characters are constructed as subjects, the meanings they embodied could have been used for transformative purposes, for viewers to see the women become fully emancipated (Tan 10). The film creators however, say that it is enough to have shown the female characters' capacity and ability to survive (Tan 30).

In these portrayals of Filipino women during the decade, the stereotypes of women as homemakers and sex objects are still dominant in both TV advertisements and films. The presence of the virgin/vamp dichotomy being subjected to the male gaze is also observed in both melodramatic and sexy films. There are portrayals of strong female characters in some films (such as those studied by Tan), although they do not achieve full emancipation due to forces of society such as politics, economy, and culture.

In the same manner, the Sexbomb Girls also reflected similar images of women that were presented in media at the time. They portrayed images of the virgin/ vamp who exuded both innocence and sexuality and were subjected to the male gaze, as well as the metaphors of the ordinary woman and the loud woman. These images similarly portrayed by the Sexbomb Girls, as well as several women in films and TV advertisements, reinforce the same myths that continue to naturalize and stereotype women into these roles.

The Sexbomb Girls' image, composed physically of the same sexy costumes and long-flowing hair-and complemented by a carefully crafted balance of provocative and at the same time child-like choreography, songs, and languageshow how media can creatively construct complex images that unconsciously seep into people's everyday lives, such that they become normal or ordinary. According to Dyer, media serves to influence and reinforce how people believe they can or should behave in society (7).

These binary oppositions portrayed by the Sexbomb Girls such as virgin/vamp, the loud woman and the ordinary woman, serve to naturalize cultural practices. These images evolve into myths that reflect, influence, or reinforce values and beliefs in a culture. The Sexbomb Girls' various images of being playful yet seductive (virgin/vamp), of being ordinary women that other women can relate to and aspire to become, and of being loud women who call attention to themselves through their actions and appearance, are reinforced into the consciousness of the Filipino audiences day in and day out that they became part of Philippine culture in the 20oos. To the audiences who have seen the Sexbomb Girls every day in Eat Bulaga, sexy background dancers chanting and gyrating in a noontime show become the norm. According to Ed Ramos: 
Eat Bulaga dropped one of its biggest bombs on noontime TV with the introduction of the all-female sing-and-dance group in 1999, sending shockwaves among viewers that weren't used to such display of hotness in the ungodly hour of lunchtime. Led by Rochelle Pangilinan, their first routines included flips and turns in miniskirts and tops with low necklines. They later tamed down their look but the Tom Jones song was nevertheless a perfect fit.

The Sexbomb Girls were the first of its kind: sexy, female background dancers placed in a daily noontime show. In the history of Philippine daytime television, all sorts of successful and innovative segments have been introduced, such as Student Canteen's singing contest "Search for the Student Canteener," Salo-Salo Together's segment "Katok Mga Misis," and Sunday Pinasaya's comic routines. Many famous actors and comedians have also been discovered or introduced in these daytime variety shows, such as Aiza Seguerra, Alden Richards, and Maine Mendoza (Eat Bulaga), Jon Santos (Lunch Date), and Jean Garcia (Kalatog Pinggan), to name a few (Harvey). However, the Sexbomb Girls' inclusion in Eat Bulaga in 1999 gave a new ingredient to Philippine TV viewing-sexy female background dancerswhich has since then been a staple in many noontime and daytime variety shows.

For fans who saw a part of themselves in the Sexbomb Girls (primarily because of their ordinariness), the female group showed that the dream of a better life could be achieved. As Sexbomb leader Rochelle Pangilinan explained, "Di ba, kaya kami sumikat, dahil 'yong mga sayaw namin ay pangmasa. 'Di ba, kahit sino puwedeng gumaya, mapatanda o mapabata?" (Asuncion 46-52).

Inarguably, the Sexbomb Girls were phenomenal and well-loved by the masses in the 2ooos. Furthermore, they were wholesome and yet possessed sex appeal that the masses believed they could reach. However, many critics believed that the Sexbomb image was a ploy that used sex to up the numbers in the ratings game. “GMA-7's Eat Bulaga struck pay dirt when it unveiled the Sexbomb Girls in their skimpy costumes gyrating to Bakit Papa? and Spageti. How their presence had to do with the show's Laban o Bawi portion, which is a quiz show, stumped me no end. But one doesn't quarrel with ratings" ("Willie Revillame").

Rival network ABS-CBN followed GMA's strategy and launched their own back-up dancers, the Gee Girls in Magandang Tanghali Bayan, but the latter did not match the success of the Sexbomb Girls. The Sexbomb Girls became a formula that added success to noontime shows, and thus, now, noontime and game shows are not complete without sexy back-up dancers gyrating during game segments. In 2018, shows such as Wowowin, Eat Bulaga, and It's Showtime have these women assisting in game segments (e.g., handing a prize to a winner) or merely serving as background entertainment. In It's Showtime and Wowowin, the costumes have 
become even more revealing, and the choreography more provocative than during the time of the Sexbomb Girls, but the audiences have become used to seeing these gyrating women in the game shows. This is what the Sexbomb Girls has done to influence our society: they have desensitized the audiences into accepting their images as a natural part of our Philippine culture. After the shock value has worn off, critics have moved on to other aspects of popular culture, and sexy female background dancers in game shows have become an ordinary part of the local TV viewing experience. 


\section{Works Cited}

Asuncion, Andrew. “Sexbomb Dancers." Yes! Magazine, March 2003, pp. 46-52.

Atienza, Glecy. "'E Anong Nakakatawa?" Isang Pagsisipat sa mga Mga Komedyanteng Babae sa Ilang Pelikulang Komedi." Pelikula Magazine: Journal of Philippine Cinema, March-August 2001, pp. 13-15.

Benedict, Helen. Virgin or Vamp: How the Press Covers Sex Crimes. Oxford UP, 1992.

Cabanawan, Erika Jean. "Women in Filipino Religion-Themed Films." Review of Women's Studies, vol. 20, no. 1-2, 2010, pp. 33-65.

Catolico, Gianna F. "Look: Former SexBomb Girls unite." Inquirer.net, 4 July 2017, entertainment.inquirer.net/232869/look-former-sexbomb-girls-reunite. Accessed 10 July 2017.

Chandler, Daniel. Semiotics: The Basics. Routledge, 2002.

Cruz, Isagani R. "Si Lam-ang, si Fernando Poe Jr., at si Aquino: Ilang Kuro-Kuro tungkol sa Epikong Filipino." Communication and Media Theories, edited by Rolando B. Tolentino, Patrick F. Campos, Randy Jay C. Solis and Choy S. Pangilinan, U of the Philippines P, 2014, pp. 207-216.

David, Jerrick Josue. "Dulsita, ang Kabuuan ng Kontradiksyon ng Imahen ni Sharon Cuneta sa Pelikulang Filipino." Kritika Kultura, vol. 25, 2015, pp. 314-343.

Domingo, Gay Ace. “Sexbomb Girls: Dance Divas." Yes! Magazine, June 2003, pp. 34-38.

Dyer, Richard. Heavenly Bodies: Film Stars and Society. 1st ed. Macmillan Education, 1987.

--. Stars. BFI Publishing, 1979.

Ellery, Lucinda. "Hair and history. Why hair is important to women." Huffingtonpost. com, 7 Sept. 2014, www.huffingtonpost.com/lucinda-ellery/hair-history-why-hairis-_b_5567365.html. Accessed 1 Aug. 2017.

Fabry, Merrill. "Now you know: How did long hair become a thing for women?" Time.com, 17 June 2016, time.com/4348252/history-long-hair. Accessed 1 Aug. 2017.

Hall, Edward T. The Hidden Dimension. Doubleday, 1966.

Harvey, Janus D. "8 kick-ass Pinoy noontime shows of yesteryear" 8list.ph, 12 Sept. 2013, 8list.ph/philippine-noontime-tv-shows. Accessed 1 Aug. 2017.

Hatton, Erin, and Mary Nell Trautner. "Equal Opportunity Objectification? The Sexualization of Men and Women on the Cover of Rolling Stone." Sexuality \& Culture, vol. 15, no. 3, 2011, pp. 256-278. Springer, doi:10.1007/s12119-011-9093-2.

“Jologs." Urban Dictionary, contributed by kei_blue, 23 Sept. 2003, www.urbandictionary. com/define.php?term=jologs. Accessed 21 Feb. 2019.

Littlejohn, Stephen W. Theories of Human Communication. $7^{\text {th }}$ Edition. Wadsworth, 2002.

Manalo, Ino. "Maria Clara as Mary Magdalene? A fresh look at 'Noli”' Inquirer.net, 24 June 2012, lifestyle.inquirer.net/53985/maria-clara-as-mary-magdalene-a-fresh-look-at-noli/. Accessed 1 Aug. 2017.

Mitchell, WJT. Iconology: Image, Text, Ideology. U of Chicago P, 1986.

Mulvey, Laura. "Visual Pleasure and Narrative Cinema." Visual and Other Pleasures: Collected Writings (Language, Discourse, Society), Macmillan, 1989, pp. 381-389. 
Parungao, Regina Mae. "Still the Bomb." mb.bom.ph, 2 Jan. 2017, entertainment.mb.com. ph/2017/01/o2/still-the-bomb/. Accessed 1 Aug. 2017.

Prieler, Michael, and Dave Centeno. "Gender Representation in Philippine Television Advertisements." Sex Roles, vol. 69, no. 276, 2013. SpringerLink, doi.org/10.1007/ S11199-013-0301-4.

Ramos, Ed. "37 incredible things that Eat Bulaga! has given us." FHM.com.ph, 20 Aug. 2016, www.fhm.com.ph/lifestyle/entertainment/eat-bulaga-history-a256-2016082o-lfrm5. Accessed 1 Aug. 2017.

Ramos, Enrique. "FHM 100 sexiest women in the world 2003." FHM Philippines, July 2003, pp. 16-19, 21, 26, 30.

Reyes, Soledad S. Reading Popular Culture. Ateneo de Manila UP, 1991.

Richards, K. "Women continue to be sexualized and misrepresented in ads, even in 2017." Adweek.com, 26 Sept. 2017, www.adweek.com/brand-marketing/women-continue-tobe-sexualized-and-misrepresented-in-ads-even-in-2017/. Accessed 1 Aug. 2017.

Sanchez, Louie Jon A. "Si Judy Ann at ang Wika ng Teleserye." Kritika Kultura, vol. 25, 2015, pp. 344-378.

Slade, Margot. "The long and the short of it: The 'meaning' of hair." Chicagotribune.com. 7 Aug. 1987, articles.chicagotribune.com/1987-08-07/features/8702280087_1_hairfemininity-and-softness-psychologists. Accessed 1 Aug. 2017.

Tan, Katrina Ross A. "Women as Articulations of Nation-Space and an Agency of Insularity: An Analysis of Selected Films by Jeffrey Jeturian." Review of Women's Studies, vol. 20, no. 1-2, 2010, pp. 5-32.

Tolentino, Rolando B. "Judy Ann Santos at ang Aura ng Ordinaryo." Richard Gomez at ang Mito ng Pagkalalake, Sharon Cuneta at ang Perpetwal ng Birhen at Iba Pang Sanaysay Ukol sa Bida sa Pelikula Bilang Kultural na Texto. Anvil, 200o, pp. 103-109.

--. "Masses, Power, and Gangsterism in the Films of Joseph 'Erap' Estrada." Communication and Media Theories, edited by Rolando B. Tolentino, Patrick F. Campos, Randy Jay C. Solis and Choy S. Pangilinan. U of the Philippines P, 2014, pp. 257-271.

--. "Rosanna Roces at ang Maingay na Babae." Richard Gomez at ang Mito ng Pagkalalake, Sharon Cuneta at ang Perpetwal ng Birhen at Iba Pang Sanaysay Ukol sa Bida sa Pelikula Bilang Kultural na Texto. Anvil, 200o, pp. 83-102.

--. "Sharon Cuneta at ang Perpetwal ng Birhen." Richard Gomez at ang Mito ng Pagkalalake, Sharon Cuneta at ang Perpetwal ng Birhen at Iba Pang Sanaysay Ukol sa Bida sa Pelikula Bilang Kultural na Texto. Anvil, 200o, pp. 63-81.

Van Leeuwen, Theo. Speech, Music, Sound. Macmillan, 1999.

Whitbourne, Susan K. "Do sexy women really feel good about themselves? Sexualization and a woman's sense of self-esteem. Psychologytoday.com, 16 Oct. 2012, www. psychologytoday.com/blog/fulfillment-any-age/20121o/do-sexy-women-really-feelgood-about-themselves. Accessed 1 Aug. 2017

"Willie Revillame: What's wrong with noontime shows." PlanetPhilippines.com, S2invisionfree.com/GeegirlsForum/index.php?showtopic=265. Accessed 30 Jul. 2017. 
Wookey, Melissa L., Nell A. Graves, and J. Corey Butler. "Effects of a Sexy Appearance on Perceived Competence of Women." Journal of Social Psychology, vol. 149, no. 1, pp. 116118. NCBI, doi: 10.3200/SOCP.149.1.116-118.

Yap, Tim. "The Sexbomb singers: Baby, they can turn you on!" Inquirer News Service, 26 June 2004, www.pinoyexchange.com/discussion/161696/the-sexbomb-girls/p17. Accessed 20 Feb. 2019. 